\title{
Qualidade da cebola influenciada pelo estádio de maturação da planta na colheita
}

\author{
Sandra Oliveira de Souza ${ }^{1}$, Fernanda Cristina Silva², Fernando Luiz Finger ${ }^{3}$, Vicente Wagner Dias Casali³, \\ Paulo Roberto Cecon ${ }^{4}$
}

\begin{abstract}
RESUMO
O objetivo deste trabalho foi avaliar a qualidade dos bulbos de duas variedades de cebola colhidos em três estádios de maturação da planta. Bulbos das variedades Texas Grano e Baia Periforme foram colhidos em 2006 no campo experimental da Universidade Federal de Viçosa, de plantas com 10\% de estalo natural, 10\% de estalo induzido e 50\% de estalo natural. Na colheita foram avaliados a massa da matéria fresca total, o diâmetro, a cor $\left(L^{*}, a^{*}\right.$ e $\left.b^{*}\right)$, o teor de massa da matéria seca, os sólidos solúveis totais e o teor relativo de água da polpa e das películas externas do bulbo. No cultivar Texas Grano, a massa da matéria fresca total, o diâmetro e os teores de sólidos solúveis totais foram maiores nos bulbos colhidos com 10 e 50\% de estalo natural. O teor relativo de água das películas externas de bulbos variedade Texas Grano foi maior somente quando colhidos com $10 \%$ de estalo natural, o que representa bulbos com películas mais úmidas. Bulbos colhidos com $10 \%$ de estalo natural e $10 \%$ de estalo induzido tiveram valores de $L^{*}$ maiores do que aqueles colhidos com $50 \%$ de estalo natural, indicando que a antecipação da colheita reduz a intensidade da cor das películas. O menor valor de $b^{*}$ para a película do bulbo da Texas Grano, colhido com $10 \%$ estalo natural, decorre do amarelo menos intenso da casca. No cultivar Baia Periforme, os índices de maturação não influenciaram a massa da matéria fresca total, o diâmetro, teor de massa da matéria seca, o teor de sólidos solúveis totais e os índices de cor $a^{*}$ e $b^{*}$. O estádio de maturação da planta, na colheita, não influencia o tamanho e o teor de sólidos solúveis dos bulbos na variedade Baia Periforme. Para a Texas Grano, bulbos maiores, com películas mais amareladas e menor teor de umidade são obtidos quando a colheita é realizada com 50\% de estalo natural.
\end{abstract}

Palavras-chave: Allium cepa, bulbos, variedades, cor da película.

\section{ABSTRACT}

\section{Effect of plant maturity at harvest on onion quality}

Bulbs of varieties Texas Grano and Baia Periforme were harvested from plants with 10 \% natural top plant collapse, $10 \%$ induced top collapse and $50 \%$ natural top collapse in the experimental field of Federal University of Viçosa, in 2006 . The following parameters were evaluated at harvest: total fresh mass, diameter, color $\left(L^{*}, a^{*}\right.$ and $\left.b^{*}\right)$, dry matter content, total soluble solids, relative water content from the pulp and skin of the bulb. 'Texas Grano' had higher total fresh mass, diameter and total soluble solids for bulbs harvested at 10 and $50 \%$ natural top collapse. Relative water content of the skin of 'Texas Grano’ was higher for bulbs harvested with $10 \%$ natural top collapse, which had higher water content. Bulbs harvested at $10 \%$ natural top collapse and $10 \%$ induced top collapse had higher $L^{*}$ values compared with 50 \% natural top collapse, showing less color intensity for the skin. Lower values of $b^{*}$ for 'Texas Grano' skin in $10 \%$ natural top collapse results from less external yellowing. Plant maturity of 'Baia Periforme'did not affect

\footnotetext{
Recebido para publicação em agosto de 2009 e aprovado em outubro de 2010

Engenheiro-Agrônomo, DS. IFET Sertão de Pernambuco, BR 235 km 22, Projeto Senador Nilo Coelho N4, 56300-000 Petrolina, PE. Caixa Postal 178. sandraosouza@yahoo.com.br

Engenheiro-Agrônomo. Departamento de Fitotecnia, UFV, Av. PH Rolfs, s/n, 36570-000 Viçosa, MG. nandsilva@yahoo.com.br

3 Engenheiro-Agrônomo, DS. Departamento de Fitotecnia, UFV, Av. PH Rolfs, s/n, 36570-000 Viçosa, MG. ffinger@ufv.br; vwcasali@ufv.br

${ }^{4}$ Engenheiro-Agrônomo, DS. Departamento de Estatística, UFV, Av. PH Rolfs, s/n, 36570-000 Viçosa, MG. cecon@ufv.br
} 
total fresh mass, diameter, dry matter content, total soluble solids and $a^{*}$ and $b^{*}$ values. Thus 'Baia Periforme' has similar bulb size and quality regardless the maturity index used. 'Texas Grano’ shows larger bulbs and yellowish and drier skin when harvested with $50 \%$ natural top collapse.

Key words: Allium cepa, bulbs, skin color, varieties.

\section{INTRODUÇÃO}

A cebola (Allium cepa L.), dentre as espécies olerícolas cultivadas do Allium, é a mais importante do ponto de vista de volume do consumo e valor econômico (Souza \& Resende, 2002).

Dados da produção mundial de cebola mostram que no ano de 2009 foram produzidos 72,3 milhões de toneladas, com produtividade média de 19,6 t ha-1 (FAO, 2010). O Brasil no mesmo ano produziu 1.413 mil toneladas, com produtividade média de $22 \mathrm{t} \mathrm{ha}^{-1}$, porém não há dados sobre a qualidade e as perdas na colheita e durante o armazenamento.

O estádio de maturidade da planta na colheita pode influenciar o tamanho, a qualidade, a porcentagem de brotação, a perda de massa total dos bulbos e a incidência de podridões pós-colheita dos bulbos (Finger \& Casali, 2002). A maturação da planta de cebola é determinada pelo amolecimento da região inferior do pseudocaule (pescoço), que resulta no subsequente tombamento (estalo) da parte aérea sobre o solo. Esse aspecto da morfologia da planta tem sido utilizado como índice prático na colheita dos bulbos, porém existem variações entre as variedades quanto à taxa, à uniformidade e à porcentagem mínima de plantas tombadas no solo ao iniciar a colheita (Soares et al., 2004).

Tradicionalmente, a colheita da cebola é realizada quando as plantas estão estaladas ou com o colo completamente amolecido. Segundo um dos primeiros trabalhos sobre colheita de cebola, a mesma deverá ser iniciada quando cerca de 15 a 35\% das plantas estiverem estaladas (Coelho, 1975). Mais recentemente, no entanto, para Wall \& Corgan (1994), se a colheita for antecipada para 20\% de plantas estaladas, os bulbos colhidos serão menores. Brewster (1994) recomenda colher os bulbos quando, no campo, 50 e $80 \%$ do total das plantas estiver com o pescoço amolecido e a folhagem iniciando seu tombamento sobre o solo. Outros autores orientam a colheita quando $50 \%$ das plantas estiverem estaladas e $25 \%$ secas (Finger \& Casali, 2002). Contudo, nesses trabalhos não é informado se existem diferenças entre as variedades com relação à qualidade dos bulbos no momento da colheita.

Os maiores rendimentos de bulbos são obtidos quando as plantas permanecem intactas até as folhas estarem completamente secas (Gubb \& Mactavish, 2002). Em cebolas colhidas antecipadamente (considerada imatura ou verde), há menor teor de sólidos solúveis, acarretando perda de algumas propriedades (Finger \& Casali, 2002). Outros trabalhos indicam maior rendimento quando a colheita é realizada após o estalo das folhas (Wall \& Corgan, 1994; Sargent et al., 2001). Segundo Sargent et al. (2001), nas colheitas tardias há aumento no rendimento total e na proporção de bulbos grandes (diâmetro > $75 \mathrm{~mm}$ ) e decréscimo na taxa respiratória, na brotação e na perda de massa nos híbridos precoces Granex e Texas Grano. Kepka \& Sypien (1991) afirmam que o atraso da colheita acarreta queda da qualidade dos bulbos, exercendo significativo efeito sobre a produção comercializável. Além disso, quando a cebola permanece por muito tempo no campo, o colo ou pescoço do bulbo fica sujeito a queimaduras de sol e as películas superficiais podem se soltar, aumentando assim a incidência de doenças (Soares et al., 2004).

A aparência externa e a massa ou volume dos bulbos são importantes componentes da qualidade da cebola. Há preferência no consumo in natura por bulbos médios, forma periforme, casca intacta e amarelo-escura (Soares et al., 2004). Além disso, o conteúdo de massa da matéria seca, número e a firmeza das películas externas depois da cura influenciam a conservação pós-colheita.

O objetivo deste trabalho foi avaliar a qualidade dos bulbos de duas variedades de cebola colhidos em três estádios de maturação da planta.

\section{MATERIAL E MÉTODOS}

O experimento foi conduzido em 2006 na área experimental da Universidade Federal de Viçosa, município de Viçosa, Minas Gerais ( $21^{\circ} 07^{\prime}$ S, 42 ${ }^{\circ}$ 57’ W e $651 \mathrm{~m}$ de altitude), com topografia plana e solo classificado como Argiloso Câmbico fase terraço. A semeadura, o transplantio e a condução da cultura seguiram as técnicas recomendadas para a cultura da cebola na região da Zona da Mata de Minas Gerais (Silva et al., 2005). O delineamento experimental foi inteiramente ao acaso no esquema fatorial com três estádios de maturação e duas variedades com 12 repetições de um bulbo.

O estalo da planta foi caracterizado pelo murchamento do pseudocaule e tombamento da folhagem. Foram avali- 
adas 36 plantas em cada variedade, sendo colhidos 12 bulbos para cada época de colheita das plantas com 10\% de estalo natural (10\% EN), $10 \%$ de estalo induzido (10\% EI) e $50 \%$ de estalo natural ( $50 \%$ EN) das variedades Texas Grano (TG) e Baia Periforme (BP), caracterizadas como de ciclos precoce e médio, respectivamente. A colheita dos bulbos a partir de plantas com 10\% EN foi feita quando havia $10 \%$ da população de plantas estaladas naturalmente. Ainda nessa ocasião induziu-se o estalo em outra parcela da população de plantas (tombamento feito manualmente na inserção do pseudocaule com o bulbo), que foi caracterizado como $10 \%$ EI, sendo a colheita desses bulbos realizada após sete dias do estalo induzido. Colheram-se os bulbos a partir de plantas com $50 \%$ EN quando havia 50\% da população de plantas de cada parcela estalada naturalmente.

Após a colheita, procedeu-se ao toalete (eliminação das raízes rente aos bulbos e das folhas a três centímetros de altura do pseudocaule) e à determinação da massa total de todos os bulbos colhidos. Em seguida, os bulbos foram armazenados à temperatura média ambiente de 21 ${ }^{\circ} \mathrm{C}$ e umidade relativa média do ar de $73 \%$, em um galpão arejado, durante 60 dias. Os bulbos foram acondicionados em redes de polietileno e dependurados em estrados de madeira.

No momento da colheita foram determinados a massa da matéria fresca do bulbo (g), o diâmetro (mm), a cor ( $L^{*}$, $a^{*}$ e $\left.b^{*}\right)$, o teor de massa da matéria seca (\%), o teor de sólidos solúveis totais ( $\left.{ }^{\circ} \mathrm{Brix}\right)$, o teor relativo de água da polpa (\%) e o teor relativo de água da película externa (\%). Nas 36 plantas de cada variedade foi determinado o diâmetro do bulbo na região central com o auxílio de um paquímetro manual. A cor das películas da cebola foi determinada por meio do colorímetro Minolta (modelo Color Reader CR-10, Japão), o qual expressa a cor em três parâmetros $\left(L^{*}, a^{*} e b^{*}\right)$, que, integralizados no diagrama, mostram a coloração do produto. O parâmetro $L$ indica a variação da coloração de preta a branca, em uma escala de 0 a 100, em que o valor 0 indica o preto e o 100, o branco (Lancaster et al., 1997). O $a^{*}$ é definido pela transição do verde (-) ao vermelho $\left(^{+}\right)$e o $b^{*}$ representa a transição do azul (-) ao amarelo (+).

O teor de massa da matéria seca nos bulbos foi estimado a partir da massa da matéria fresca do bulbo após secagem em estufa de ventilação forçada a $80^{\circ} \mathrm{C}$ até atingir massa constante. $\mathrm{O}$ teor de sólidos solúveis totais foi determinado em amostras homogeneizadas do bulbo, determinado em refratômetro de balcão Atago modelo 3T, ajustado à temperatura de $25{ }^{\circ} \mathrm{C}$. Os teores relativos de água da polpa e da película mais externa foram determinados em discos de 0,8 e 1,4 cm de diâmetro, retirados da região equatorial do bulbo, respectivamente como descrito previamente por Catsky (1974).
Os dados foram submetidos à análise de variância e as médias, comparadas por meio do teste de Tukey, a 5\% de probabilidade.

\section{RESULTADOS E DISCUSSÃO}

Houve efeito da interação entre o estádio de maturação e a variedade quanto à massa dos bulbos. No cultivar Texas Grano os bulbos colhidos com 10\% EN (82,2 g) e $50 \%$ EN (68,7 g) de maturação apresentaram valores da massa da matéria fresca maiores $(\mathrm{p}<0,05)$ que os colhidos com 10\% EI (40,2 g), enquanto na variedade Baia Periforme não houve influência de estádio de maturação da planta sobre a massa da matéria fresca do bulbo (Tabela 1). A massa dos bulbos de Baia Periforme foi maior ( $\mathrm{p}<$ $0,05)$ que dos bulbos de Texas Grano nos estádios de maturação 50\% EN e 10\% EI. (Tabela 1).

O diâmetro de bulbos da variedade Texas Grano foi menor $(\mathrm{p}<0,05)$ nas colheitas com $10 \%$ EI $(38,4 \mathrm{~mm})$ do que naqueles colhidos com 10\% EN (53,0 mm) e 50\% EN (49,8 $\mathrm{mm}$ ) (Tabela 1). Esse resultado indica que, neste cultivar, com $10 \%$ de plantas estaladas ainda há crescimento subsequente dos bulbos ainda imaturos, havendo, portanto, a necessidade do estalo natural para haver a paralisação do seu crescimento. Os teores médios de massa da matéria seca dos bulbos foram maiores $(\mathrm{p}<0,05)$ na Baia Periforme (11,6\%) do que na Texas Grano (7,0\%), não havendo influência dos estádios de maturação da planta sobre esta variável. Soares et al. (2004) encontraram valores similares de massa da matéria seca na variedade Baia Periforme $(11,5 \%)$ e no híbrido Granex (6,8\%). As variações no teor de massa da matéria seca encontradas nos bulbos foram mais relacionadas principalmente com as variedades do que com o estádio de maturação da planta no momento da colheita.

Os teores de sólidos solúveis totais na variedade Texas Grano foram maiores $(\mathrm{p}<0,05)$ nos bulbos colhidos de plantas com $10 \%$ EN ( $\left.8,6^{\circ} \mathrm{Brix}\right)$ e $50 \%$ EN $\left(9,1^{\circ} \mathrm{Brix}\right)$ do que naqueles de plantas com $10 \%$ EI (6,7 $\left.{ }^{\circ} \mathrm{Brix}\right)$. Na variedade Baia Periforme, não se verificou influência do estádio de maturação da planta sobre os teores de sólidos solúveis totais do bulbo. Os teores de sólidos solúveis na Baia Periforme foram maiores $(\mathrm{p}<0,05)$ do que na Texas Grano em todos os estádios de maturação. Segundo Kopsell \& Randle (1997), as variedades tardias ou exigentes em fotoperíodo longo têm maior teor de sólidos solúveis totais do que as cebolas precoces ou de dias curtos, como a Texas Grano. Entretanto, Sinclair et al. (1995) verificaram pequena influência da maturação da planta sobre o teor de sólidos totais, sendo maior a contribuição genética na maioria das variedades de ciclos precoce e tardio.

O teor relativo de água da polpa foi maior $(\mathrm{p}<0,05)$ na Texas Grano (76,7\%) do que na Baia Periforme (64,3\%) somente quando os bulbos foram colhidos de plantas com 
10\% EN (Tabela 1). O teor relativo de água da película externa foi maior $(\mathrm{p}<0,05)$ nos bulbos colhidos de plantas com $10 \%$ EN (28,3\%) na variedade Texas Grano, provavelmente devido à colheita precoce, sendo aproximadamente o dobro dos colhidos com 10\% EI (15,7\%) e 50\% EN (13,3\%). No entanto, o alto teor relativo de água da película externa encontrada nos bulbos colhidos de plantas com $10 \%$ EN na variedade Texas Grano indica que com esse índice de maturação há excesso de umidade na casca quando comparado com a colheita de plantas 10\% EI e $50 \%$ EN. O teor relativo de água da película externa do bulbo na variedade Baia Periforme foi semelhante nos diferentes estádios de maturação da planta e menor que o da Texas Grano colhido com 10\% EN, 10\% EI e 50\% EN, indicando que na Baia Periforme há melhor desidratação e consequente cura das películas externas (Tabela 1).
Os valores médios do parâmetro de cor $L^{*}$ nos bulbos colhidos de plantas com 10\% EN e 10\% EI, em ambas as variedades, foram maiores ( $p<0,05)$ do que naqueles obtidos de plantas com 50\% EN. Isso indica que os bulbos colhidos com maior percentual de plantas tombadas no solo têm coloração mais escura, provavelmente em razão de sua maior permanência nas condições ambientais de campo. Sanguansri \& Sutherland (1991) ressaltam que nos bulbos expostos a altas temperaturas aumenta a concentração de pigmentos naturais nas películas externas durante o processo de cura, resultando em coloração mais escura. Os maiores valores de $L$ na Texas Grano em relação à Baia Periforme indicam que os bulbos da Baia Periforme têm coloração mais escura do que os da Texas Grano.

Tabela 1. Valores médios de massa da matéria fresca (MF), diâmetro (D), teor de massa da matéria seca (TMS), teor de sólidos solúveis totais (SST), teor relativo de água da polpa (TRPOL) e teor relativo de água das películas externas (TRPEL), após a colheita de plantas com $10 \%$ de estalo natural (10\% EN), $10 \%$ de estalo induzido (10\% EI) e 50\% de estalo natural (50\% EN), nas variedades Texas Grano (TG) e Baia Periforme (BP)

\begin{tabular}{|c|c|c|c|c|c|}
\hline \multirow{2}{*}{$\begin{array}{l}\text { Característica } \\
\text { avaliada }\end{array}$} & \multirow{2}{*}{ Variedade } & \multicolumn{3}{|c|}{ Estádio de maturação } & \multirow{2}{*}{ Média } \\
\hline & & $10 \% \mathrm{EN}$ & $10 \%$ EI & $50 \%$ EN & \\
\hline \multirow{2}{*}{ MF (g) } & TG & $82,2 \mathrm{Aa}$ & $40,2 \mathrm{Bb}$ & $68,7 \mathrm{Ab}$ & 63,7 \\
\hline & $\mathrm{BP}$ & 78,3 Аа & 88,8 Аа & 96,0 Аа & 87,7 \\
\hline \multirow{2}{*}{$\mathrm{D}(\mathrm{mm})$} & TG & $53,0 \mathrm{Aa}$ & $38,4 \mathrm{Bb}$ & 49,8 Аа & 47,1 \\
\hline & BP & 51,5 Аа & 52,9 Аа & 53,4 Аа & 52,6 \\
\hline \multirow[t]{2}{*}{ TMS (\%) } & TG & 6,7 Ab & 7,1 Ab & 7,2 Ab & 7,0 \\
\hline & $\mathrm{BP}$ & 11,3 Аа & $11,5 \mathrm{Aa}$ & 11,9 Аа & 11,6 \\
\hline \multirow{2}{*}{ SST $\left({ }^{\circ}\right.$ Brix $)$} & TG & 8,6 Ab & 6,7 Bb & 9,1 Ab & 8,1 \\
\hline & $\mathrm{BP}$ & 11,4 Аа & 11,3 Аа & 10,6 Аа & 11,1 \\
\hline \multirow{2}{*}{ TRPOL (\%) } & TG & 76,7 Аа & 70,9 Аа & 77,6 Аа & 75,1 \\
\hline & $\mathrm{BP}$ & $64,3 \mathrm{Ab}$ & 64,1 Аа & 67,0 Аа & 65,1 \\
\hline \multirow{2}{*}{ TRPEL (\%) } & TG & $28,3 \mathrm{Aa}$ & $15,7 \mathrm{Ba}$ & $13,3 \mathrm{Ba}$ & 19,1 \\
\hline & $\mathrm{BP}$ & 8,1 Ab & $10,9 \mathrm{Ab}$ & 9,2 Ab & 9,4 \\
\hline
\end{tabular}

Médias seguidas pela mesma letra maiúscula na linha e minúscula na coluna, para cada variável, não diferem entre si a 5\% de probabilidade, pelo teste de Tukey.

Tabela 2. Valores médios de cor $\left(L^{*}, a^{*}\right.$ e $\left.b^{*}\right)$ das películas externas, após a colheita de bulbos de plantas com 10\% de estalo natural (10\% EN), $10 \%$ de estalo induzido (10\% EI) e 50\% de estalo natural (50\% EN), nas variedades Texas Grano (TG) e Baia Periforme (BP)

\begin{tabular}{|c|c|c|c|c|}
\hline \multirow{2}{*}{ Parâmetro } & \multirow{2}{*}{ Variedade } & \multicolumn{3}{|c|}{ Estádio de maturação } \\
\hline & & $10 \% \mathrm{EN}$ & $10 \% \mathrm{EI}$ & $50 \% \mathrm{EN}$ \\
\hline \multirow{2}{*}{$L^{*}$} & TG & $74,3 \mathrm{Aa}$ & $70,5 \mathrm{Aa}$ & $62,1 \mathrm{Ba}$ \\
\hline & BP & $59,7 \mathrm{Ab}$ & $52,4 \mathrm{Ab}$ & $48,9 \mathrm{Bb}$ \\
\hline \multirow{2}{*}{$a^{*}$} & TG & $10,0 \mathrm{Ab}$ & 12,7 Аа & $12,6 \mathrm{Ab}$ \\
\hline & $\mathrm{BP}$ & $14,4 \mathrm{Aa}$ & 16,5 Аа & 17,9 Аа \\
\hline \multirow{2}{*}{$b^{*}$} & TG & $18,6 \mathrm{Bb}$ & $22,9 \mathrm{Aa}$ & 22,1 Aa \\
\hline & BP & 22,9 Аа & 20,5 Аа & 22,8 Aa \\
\hline
\end{tabular}

Médias seguidas pela mesma letra maiúscula na linha e minúscula na coluna, para cada variável, não diferem entre si a 5\% de probabilidade, pelo teste Tukey. 
Os estádios de maturação não influenciaram isoladamente os valores de $a^{*}$ de bulbos das variedades Texas Grano e Baia Periforme. Porém, os maiores valores de $a^{*}$ de bulbos da Baia Periforme ( $<<0,05)$ do que os da Texas Grano, de plantas colhidas com 10\% EN e 50\% EN indicam que os bulbos da Baia Periforme tiveram coloração menos esverdeada do que os da Texas Grano.

Na variedade Texas Grano, os valores de $b^{*}$ de bulbos foram influenciados pelo estádio de maturação da planta. Nos bulbos colhidos de plantas com 10\% EN $(18,6)$ nessa variedade os valores de $b^{*}$ foram menores $(\mathrm{p}<0,05)$ do que os obtidos em bulbos de plantas com $10 \%$ EI $(22,9)$ e $50 \%$ EN (22,1), sendo os maiores valores indicativos de coloração mais próxima do amarelo.Houve diferença ( $\mathrm{p}<$ $0,05)$ entre as variedades, tendo os bulbos da Baia Periforme $(22,9)$ apresentando valores maiores $(p<0,05)$ do que os da Texas Grano $(18,6)$ quando colhidos de plantas com $10 \%$ EN. Isso indica que os bulbos da Baia Periforme naturalmente têm coloração da casca mais próxima do amarelo do que os da Texas Grano.

\section{CONCLUSÕES}

A colheita da cebola em diferentes estádios de maturação da planta influencia a massa fresca e o diâmetro dos bulbos da variedade Texas Grano, mas não da Baia Periforme.

Os teores de matéria seca e de sólidos solúveis totais, o tamanho dos bulbos e umidade da casca na variedade Baia Periforme não são afetados pelos índices de maturação da planta.

A colheita dos bulbos da variedade Texas Grano com $50 \%$ EN resulta em bulbos maiores, com casca mais amarela e seca.

\section{AGRADECIMENTOS}

Os autores agradecem ao CNPq, pela concessão de bolsa de mestrado à primeira autora.

\section{REFERÊNCIAS}

Brewster JL (1994) Onions and other vegetables alliums. Wallingford: CAB International, $236 \mathrm{p}$.

Catsky J (1974) Water content. In: Slavik B (Ed.) Methods of studying plant water relations. Berlin: Springer-Verlag, p. 121-131.

Coelho RG (1975) Alguns aspectos sobre o armazenamento de bulbos de cebola (Allium cepa, L.). Viçosa, Editora UFV. 16p.

FAO. FAOSTAT. Disponível em:<http://faostat.fao.org/site/567/ default.aspx\#ancor>. Acessado em setembro 2010.

Finger FL \& Casalli VWD (2002) Colheita, cura e armazenamento da cebola. Informe Agropecuário, 23:93-98.

Gubb IR \& Mactavish HS (2002) Onion Pre- and Postharvest Considerations. In: Rabinowitch HD, Currah L (Eds.). Allium crop science: recent advances. Wallingford: CAB International, 515 p.
Kepka AK \& Sypien MA (1991) The influence of the some factors on the keeping quality of onions. Acta Agrobotânica, 44:65-71.

Kopsell DE \& Randle WM (1997) Onion cultivars differ in pungency and bulb quality changes during storage. HortScience, 32:1260-1263.

Lancaster JE, Lister CE, Ready PF \& Triggs CM (1997) Influence of pigment composition on skin color in a wide range of fruit and vegetables. Journal of American Society for Horticultural Science, 122:594-598.

Sanguansri P \& Sutherland J (1991) Artificial curing of onions for Victoria. Onions Australia, 8:31.

Sargent SA, Stoffella PJ \& Maynard DN (2001) Harvest date affects yield and postharvest quality of nondried short-day onions. Hortscience, 36:112-115.

Sinclair PJ, Blakeney AB \& Barlow EWR (1995) Relationships between bulb dry matter content, soluble solids concentration and non-structural carbohydrate composition in the onion (Allium cepa). Journal Science and Food Agriculture, 69:203209.

Silva, D.J.H.; Fontes, P.C.; Finger, F.L (2005) Cultura da cebola. In: Paulo C. R. Fontes (Ed). Olericultura teoria e prática. Viçosa, 355-369.

Soares VLF, Finger FL \& Mosquim PR (2004) Influência do genótipo e do estádio de maturação na colheita sobre a matéria fresca, qualidade e cura dos bulbos de cebola. Horticultura Brasileira, 22:18-22.

Souza RJ \& Resende GM (2002) Cultura da cebola. Lavras, Editora UFLA. 115 p.

Wall MM \& Corgan JN (1994) Postharvest losses from delayed harvest and during common storage of short-day onions. HortScience, 29:802-804. 